\title{
Molecular Structure, Dynamic Expression, and Promoter Analysis of Zebrafish (Danio rerio) myf-5 Gene
}

\author{
Yau-Hung Chen, Wen-Chih Lee, Chia-Feng Liu, and Huai-Jen Tsai ${ }^{\star}$ \\ Institute of Fisheries Science, National Taiwan University, Taipei, Taiwan, Republic of China
}

Received 12 August 2000; Accepted 24 October 2000

\begin{abstract}
Summary: We isolated a 1,438 bp cDNA fragment that encoded Myf-5 myogenic factor of zebrafish. The deduced amino acid contained 237 residues, including the basic helix-loop-helix domain that is conserved in all known Myf-5. The zebrafish myf-5 transcripts were first detectable at $7.5 \mathrm{hpf}$, increased substantially until $16 \mathrm{hpf}$, and then declined gradually to an undetectable level by 26 hpf. During somitogenesis, zebrafish myf-5 transcripts were distributed mainly in the somites and segmental plates. Prominent signals occurred transiently in adaxial cells in two parallel rows but did not extend beyond the positive-signal somites. Various lengths of upstream region of zebrafish myf-5 fused with EGFP gene were used to carry out transgenic analysis. Results showed that a small, 82 bp (nucleotide positions from -82 to -1 ), regulatory cassette is sufficient to control the somite- and stage-specific expression of zebrafish myf-5 during early development. genesis 29:22-35, 2001. () 2001 Wiley-Liss, Inc.
\end{abstract}

Key words: fish; microinjection; molecular structure; muscle-specificity; somitogenesis; transgenic fish

\section{INTRODUCTION}

Skeletal muscle formation during myogenesis is controlled by four basic helix-loop-helix (bHLH) transcription factors: MyoD (Davis et al., 1987), myogenin (Braun et al., 1989a; Edmondson and Olson, 1989; Wright et al., 1989), Myf-5 (Braun et al., 1989b), and MRF4/herculin/ Myf-6 (Rhodes and Konieczny, 1989; Braun et al., 1990; Miner and Wold, 1990). These bHLH factors are nuclear proteins that transactivate the expression of musclespecific genes, such as the muscle creatine kinase gene (Jaynes et al., 1988) and myosin light chain gene (Braun and Arnold, 1991; Faerman and Shani, 1993), that contain one or more E-box motifs and a DNA-binding site with the general consensus sequence CANNTG.

Each bHLH factor may play a different role during myogenesis. In situ hybridization in mouse embryos demonstrate that $m y f-5$ is the first myogenic bHLH gene to be expressed in the somites at 8.0 days postcoitum (dpc) (Ott et al., 1991), followed by myogenin at 8.5 dpc (Sassoon et al., 1989), and mrf4 at 9.0 dpc. Expres- sion of $m y o \mathrm{D}$ begins at $10.5 \mathrm{dpc}$ in myotomes, but by this stage $m y f-5$ expression is decreasing (Sassoon et al., 1989; Lyons and Buckingham, 1992). In contrast to the sequential order of bHLH gene transcripts in mice, $\mathrm{Xe}$ nopus and quail myoD are expressed in the somites before other myogenic HLH genes (Rupp and Weintraub, 1991; Pownall and Emerson, 1992). In addition, Xenopus myoD mRNA is maternally inherited (Rupp and Weintraub, 1991). Gene knockout experiments with mice showed that normal muscle development occurred when either the $m y f-5$ or $m y o \mathrm{D}$ gene was inactivated. However, transgenic mice in which both $m y f-5$ and myoD genes were disrupted did not form skeletal muscle (Rudnicki et al., 1993). Thus, myf-5 and myoD may compensate for each other to regulate skeletal muscle development.

In vertebrates, muscle fibers in the trunk and limbs are formed by myogenic cells that originate from somites (Chevallier et al., 1977; Christ et al., 1977). Somites form as epithelial balls but soon reorganize into three regions: dermatome, myotome, and sclerotome. Unlike the somites of mouse and chick, zebrafish (Danio rerio) somite gives rise to sclerotome and myotome (Kimmel et al., 1995). Somite formation of zebrafish initiates at $10.5 \mathrm{~h}$ postfertilization (hpf) and forms sequentially from anterior to posterior. One pair of new somitic furrow takes approximately $30 \mathrm{~min}$ to complete, and about 26-30 pairs of somite are formed (Kimmel et al., 1995; van Eeden et al., 1996). Embryonic expression in the skeletal muscle of zebrafish is easily observed due to the transparency, rapid development, and definite stages of the embryo. These advantages make zebrafish an excellent animal model for studying myogenesis.

Myf- 5 cDNA has been reported in some vertebrates, including humans (Braun et al., 1989b), mice (Buonanno et al., 1992), bovine (Barth et al., 1993), chickens (Saitoh

Nucleotide sequence data are in the GenBank databases under the accession numbers AF184166 and AF270789.

* Correspondence to: Huai-Jen Tsai, 1, Roosevelt Road, Sec. 4, Taipei, Taiwan 106. E-mail: hjtsai@ccms.ntu.edu.tw

Contract grant sponsor: National Science Council; Contract grant number: NSC 89-2313-B002-227. 
et al., 1993), Xenopus (Hopwood et al., 1991), and carp (Kobiyama et al., 1998). But the upstream regulatory regions of $m y f-5$ gene have been reported only in mice (Hadchouel et al., 2000; Summerbell et al., 2000). Zebrafish $m y f-5$ gene is not clearly and fully characterized so far. In addition, the transcriptional pattern of zebrafish myf-5 during the early development is also uncovered. In this study, we characterize the genomic structure and upstream sequence of zebrafish $m y f-5$ gene. We perform in situ hybridization for whole embryos to observe the initiation stage of zebrafish $m y f-5$ transcription and the spatial distribution of zebrafish $m y f-5$ transcripts during embryonic development. Furthermore, we analyze the proximal cis-regulatory elements of zebrafish $m y f-5$ gene using transgenic analysis. This information should help us understand much more about the molecular structure and regulatory mechanisms of the $m y f-5$ gene.

\section{RESULTS}

\section{Sequences of Nucleotide and Deduced Amino Acid of Zebrafish $m \boldsymbol{y} \boldsymbol{f}$ - 5 cDNA}

A 252-bp fragment was amplified by the Myf5-67F and Myf5-150R primers. A 439-bp fragment corresponding to the 5'-end, noncoding regions, was amplified with RAAPC and Myf5-150R primers. For 3' rapid amplification of cDNA ends (RACE), primers Myf5-67F and RAAPT were used for the first PCR, and primers Myf5-96F and RAUAP were used for the second PCR, resulting in an 1,105-bp fragment. The full-length cDNA of zebrafish $m y f-5$ was 1,433 bp and contained a 714-bp open reading frame with 43- and 676-bp flanking regions at the 5'and 3 '-ends, respectively (Fig. 1). The deduced amino acid sequence of zebrafish $m y f-5$ revealed a 237-aminoacid polypeptide that contained a bHLH domain located at amino acid positions 66 to 124 .

The sequence identity of the zebrafish myf-5 polypeptide bHLH domain was $82.8 \%$ with zebrafish MyoD (Weinberg et al., 1996) and 74.1\% with zebrafish myogenin (Chen et al., 2000) (Fig. 2a). However, the entire zebrafish $m y f-5$ polypeptide sequence shared only $54.3 \%$ and $40.8 \%$ amino acid identity with those of zebrafish MyoD and myogenin, respectively. The bHLH domain of the zebrafish $m y f-5$ polypeptide exhibited 100, 84.5, $86.2,82.8,84.5$, and $84.5 \%$ identity, with the Myf-5 bHLH domain from carp (Kobiyama et al., 1998), Xenopus (Hopwood et al., 1991), chickens (Saitoh et al., 1993), bovine (Barth et al., 1993), mice (Buonanno et al., 1992), and human (Braun et al., 1989b), respectively (Fig. 2b).

\section{Dynamic Expression and Spatial Distribution of Zebrafish myf-5 Transcripts}

Whole-mount in situ hybridization showed that zebrafish $m y f-5$ transcripts were first observed in the segmental plates $7.5 \mathrm{hpf}$ (Fig. 3a) and extended about two pairs of somites every hour (Figs. 3b-d). At 16-hpf embryos, about twelve pairs of somites gave positive signals for zebrafish myf-5 transcripts (Fig. 3d). After $16 \mathrm{hpf}$, the signals in the somites became weaker and weaker. The number of somites exhibiting gene expression gradually decreased from 16 to $24 \mathrm{hpf}$ (data not shown). By 24 hpf, zebrafish $m y f-5$ transcripts were present only in the last three pairs of somites close to the tail bud (Figs. 3i and 31). The zebrafish $m y f-5$ gene was expressed during segmentation. Scarcely any zebrafish $m y f-5$ transcripts were detected in the tail bud after 26 hpf (Fig. 3j). Signals for zebrafish $m y f-5$ transcripts were found in the somites, the lateral presomitic cells, and adaxial cells (Fig. 3k). The prominent bands, which occurred in adaxial cells in two parallel rows, did not extend beyond the positive-signal somites. We found that zebrafish myf-5 transcripts were expressed in a somite- and stage-specific manner.

\section{Molecular Structure of the Zebrafish myf-5 Gene}

To elucidate the mechanism underlying the regulation of zebrafish $m y f-5$ expression, we isolated the upstream, regulatory sequence of zebrafish $m y f-5$ from the zebrafish genomic library. Approximately $2 \times 10^{5}$ plaques were screened and eight were purified. Southern blot analysis revealed that one of recombinant phages contained $\mathrm{a} \approx 14 \mathrm{~kb}$ insert in which $\mathrm{a} \approx 6.6 \mathrm{~kb}$ SacI fragment encompassed the $5^{\prime}$-flanking region, and $\mathrm{a} \approx 2.4 \mathrm{~kb} S a c \mathrm{I}$ fragment encompassed 3 exons and 2 introns of the partial zebrafish $m y f-5$ genomic sequence (Figs. 4 and 5). The boundary sequences of the introns all followed to GT-AG rule.

The primer extension experiment showed that zebrafish $m y f-5$ transcription started at the $G$ located at position -48 relative to translation start site (data not shown). The first nucleotide (nt) obtained from the $5^{\prime}$ RACE product was the 6th nt of the sequence obtained from primer extension.

\section{Expression Patterns of EGFP cDNA Driven by Zebrafish $m y f-5$ Upstream Regions in Transgenic Embryos}

An exogenous DNA (pZMYP-759Et) concentration of $25 \mathrm{ng} / \mu \mathrm{l}$ was chosen for microinjection because, unlike DNA concentrations of 10 and $100 \mathrm{ng} / \mu \mathrm{l}$, it was sufficient for transgenic EGFP expression but did not cause lethal effects. To mimic the endogenous zebrafish $m y f-5$ expression pattern, EGFP cDNA fused with -3 (pZMYP2937E) and -6.3 (pZMYP-6212E) kb of zebrafish myf-5 upstream sequences were microinjected into 85 and 55 fertilized eggs, respectively. The EGFP expression patterns of these two constructs in transgenic fish were identical, except for how brightly each fluoresced. The initiation of EGFP expression occurred at the $90 \%$ epiboly stage (about $9 \mathrm{hpf}$; Fig. 6c) at the edge of a shield in a faint, but well-defined spot. During the early segmental stage (about 10-16 hpf), EGFP signals were observed in the somites and segmental plate (Fig. 6d), but the EGFP expression pattern began to change from spot to bar shaped. During the pharyngula stage (24- $48 \mathrm{hpf})$, EGFP was expressed in the somites and the peripheral layer of 
ATG GAC GTA TTC TCC ACA TCC CAG ATC TTC TAC GAC AGC ACT TGC GCT TCG TCT OCT GAA 103

$\begin{array}{llllllllllllllllllllllllllllllll}1 & \text { M } & \text { D } & \text { V } & \text { F } & \text { S } & \text { T } & \text { S } & \text { Q } & \text { I } & \text { F } & \text { Y } & \text { D } & \text { S } & \text { T } & \text { C } & \text { A } & \text { S } & \text { S } & \text { P } & \text { E } & 20\end{array}$

104 GAT TTA GAG TTT GGA GCC AGT GGG GAA CIG ACC GGG TCT GAG GAG GAT GAG CAC GTG CGG 163

$\begin{array}{llllllllllllllllllllll}21 & \mathrm{D} & \mathrm{L} & \mathrm{E} & \mathrm{F} & \mathrm{G} & \mathrm{A} & \mathrm{S} & \mathrm{G} & \mathrm{E} & \mathrm{L} & \mathrm{T} & \mathrm{G} & \mathrm{S} & \mathrm{E} & \mathrm{E} & \mathrm{D} & \mathrm{E} & \mathrm{H} & \mathrm{V} & \mathrm{R} & 40\end{array}$

164 GCT CCT GGG GCC CCA CAT CAA COG GOC CAT TGT CTC CAA TGG GOC TGC AAA GCT TGC AAG 223

$\begin{array}{lllllllllllllllllllllll}41 & \text { A } & \text { P } & \text { G } & \text { A } & \text { P } & \text { H } & \text { Q } & \text { P } & \text { G } & \text { H } & \text { C } & \text { L } & \text { Q } & \text { W } & \text { A } & \text { C } & \text { K } & \text { A } & \text { C } & \text { K } & & 60\end{array}$

224 OGT AAA GCC AGT ACG GTG GAC OGC CGG AGA GOC GOC ACC ATG AGG GAA OGG OGC AGG CTG 283

$\begin{array}{lllllllllllllllllllllll}61 & \mathrm{R} & \mathrm{K} & \mathrm{A} & \mathrm{S} & \mathrm{T} & \mathrm{V} & \mathrm{D} & \mathrm{R} & \mathrm{R} & \mathrm{R} & \mathrm{A} & \mathrm{A} & \mathrm{T} & \mathrm{M} & \mathrm{R} & \mathrm{E} & \mathrm{R} & \mathrm{R} & \mathrm{R} & \mathrm{L} & & 80\end{array}$

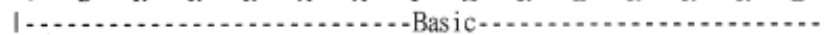

284 AAG AAG GTC AAT CAC GOC TTT GAG GCA CTA OGC CGC TGC AOC TOG GOC AAC OCT AGC CAA

$\begin{array}{lllllllllllllllllllllll}81 & \mathrm{~K} & \mathrm{~K} & \mathrm{~V} & \mathrm{~N} & \mathrm{H} & \mathrm{A} & \mathrm{F} & \mathrm{E} & \mathrm{A} & \mathrm{L} & \mathrm{R} & \mathrm{R} & \mathrm{C} & \mathrm{T} & \mathrm{S} & \mathrm{A} & \mathrm{N} & \mathrm{P} & \mathrm{S} & \mathrm{Q} & 100\end{array}$ K....

344 OGC CTC COC AAG GTA GAG ATC CTG AGG AAC GCC ATC CAG TAC ATC GAG AGC CTT CAG GAG

$\begin{array}{llllllllllllllllllllll}101 & \mathrm{R} & \mathrm{L} & \mathrm{P} & \mathrm{K} & \mathrm{V} & \mathrm{E} & \mathrm{I} & \mathrm{L} & \mathrm{R} & \mathrm{N} & \mathrm{A} & \mathrm{I} & \mathrm{Q} & \mathrm{Y} & \mathrm{I} & \mathrm{E} & \mathrm{S} & \mathrm{L} & \mathrm{Q} & \mathrm{E}\end{array}$

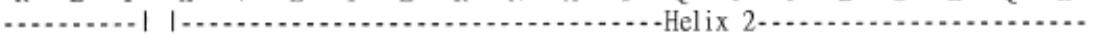

404 CTC CTC AGG GAA CAG GTG GAG AAC TAC TAC AGC CTG CCG ATG GAG AGC AGC TCT GAG COC

$\begin{array}{lllllllllllllllllllllll}121 & \mathrm{~L} & \mathrm{~L} & \mathrm{R} & \mathrm{E} & \mathrm{Q} & \mathrm{V} & \mathrm{E} & \mathrm{N} & \mathrm{Y} & \mathrm{Y} & \mathrm{S} & \mathrm{L} & \mathrm{P} & \mathrm{M} & \mathrm{E} & \mathrm{S} & \mathrm{S} & \mathrm{S} & \mathrm{E} & \mathrm{P} & 140\end{array}$ ..................

464 GCC AGT COC TCC TOC AGC TGC TCA GAG AGC ATG GTT GAC TGC AAC AGT OCT GTA TGG CCT $\begin{array}{lllllllllllllllllllllll}141 & A & S & P & S & S & S & C & S & E & S & M & V & D & C & N & S & P & V & W & P & \end{array}$

524 CAG ATG AAT CAA AAC TAT GGG AAT AGC TAC AAC TTT GAC GCA CAA AAT GCT AGC ACA ATG $\begin{array}{lllllllllllllllllllll}161 & Q & M & N & Q & N & Y & G & N & S & Y & N & F & D & A & Q & N & A & S & T & M\end{array}$

584 GAG CGA ACT CCA GGA GTG TCC AGT TTG CAG TGT TTG TCC AGC ATC GTG GAC AGA CTG TCC $\begin{array}{llllllllllllllllllllll}181 & \mathrm{E} & \mathrm{R} & \mathrm{T} & \mathrm{P} & \mathrm{G} & \mathrm{V} & \mathrm{S} & \mathrm{S} & \mathrm{L} & \mathrm{Q} & \mathrm{C} & \mathrm{L} & \mathrm{S} & \mathrm{S} & \mathrm{I} & \mathrm{V} & \mathrm{D} & \mathrm{R} & \mathrm{L} & \mathrm{S} & 200\end{array}$

644 TCT GTA GAT OCT GOG GGA ATG AGG AAC ATG GTC GTT CTT TCT CCA ACC GGA AGT GAT TCC 703

$\begin{array}{lllllllllllllllllllllll}201 & \text { S } & \text { V } & \text { D } & \text { P } & \text { A } & \text { G } & \text { M } & \text { R } & \text { N } & \text { M } & \text { V } & \text { V } & \text { L } & \text { S } & \text { P } & \text { T } & \text { G } & \text { S } & \text { D } & \text { S } & 220\end{array}$

704 CAG TOC AGT TCT CCA GAC AGT CCA AAC AAC AGA CCA GTT TAC CAC GTA CTG TGA GAAGCGA 764

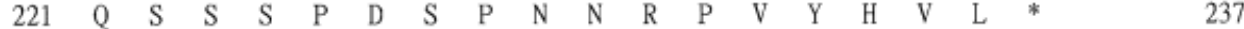

765 ACGAAGATGCCTCAGGCCAACGCTTTATTCACACTGCTTGCTCATTTGTAAATTATTTTGGATAATAATTTGATAATGC 843

844 TTTCAGAATGTAGTAATTGATCTCCATTCAGCTACAATTATAAAAACAATTGOCTTCAAAATATGCTCTAAATTGTGAA 922

923 ACAAATGTTGATTATTTCTTTGGGTCAAAGGCTGATTATAGTTTGGTTTATAGGGTCAGACTTTAAACTTAACTCGCTT 1001

1002 TAAAAAGTCAAACTATACAATGTACCAGATGTTTTTTTCACAATATTGTCTGTCTGTGTAGTTTCACTACATGGACAT 1080

1081 TGATTTATTTATCTATAATAATGATAATAATAATCACTCTGGTACTTAGTAAATGCATTTTTTTAATTATTAGOCTAAA 1159

1160 TTCTAAAAAATATTGAGTTTTTATGGACTTATTTTTAAATTACCATGTOCATATTTTACOCAAATTTGTGCAGOGTTTA 1238

1239 AATTTGATGTTGTCCTTGACCTGCCATGTTTTTTGTTGTAAATAAGATTGTACATAATTCTAAATGACATGTAATTGTA 1317

1318 TTCATGTTGTTTCTGTCATATTTAATGAACATTCTTACATAAAATGACTTGCTTTTCCAATAATAAATCTCCACAAATG 1396

1397 TGTTATTTAATAACAAAAAAAAAAAAAAAAAAAAAAA
FIG. 1. Nucleotide and deduced amino acid sequence of zebrafish myf-5 cDNA. The nucleotides were numbered beginning with the first nucleotide of 5'-RACE product $(+1)$. Numbers on the second line of each row indicate the amino acid sequences, and the notation on the third line indicates the structural motif. The polyadenylation signal (AATAAA) is shown in a gray box, and the stop codon is marked with an asterisk. The "destabilizer" sequence motifs are underlined. This nucleotide sequence is in the GenBank database under the accession number AF270789. the neural tube (Figs. 6e, g), and the expression pattern began to change from bar shaped to linear. We also observed that the EGFP fluorescent signals could translocate and changed their shapes in the somites of transgenic embryos. These linear signals lasted until the hatching and early larval period (48-72 hpf).

\section{Minimal Tissue-Specific Regulatory Sequence}

To identify the cis-acting elements in the proximal region of zebrafish $m y f-5$ promoter, we also isolated seven deletion clones that encompassed different lengths of the upstream regulatory sequence. Deletion clones of pZMYP-22E, -62E, -82E, -154E, -290E, -526E, and $-702 \mathrm{E}$ were linearized with $S t u \mathrm{I}$, and each was microinjected at a concentration of $25 \mathrm{ng} / \mu \mathrm{l}$. Embryos injected with DNA fragments containing the $-82,-154$, $-290,-526$, and -702 bp upstream sequences (pZMYP82E, $-154 \mathrm{E},-290 \mathrm{E},-526 \mathrm{E}$, and $-702 \mathrm{E}$, respectively) displayed GFP-positive signals in the somites at $10 \mathrm{hpf}$. As the total expression rates, the somite-specific rates of above groups were high (from $47 \%$ to $96.6 \%$ of survival embryos), and the nonspecific expression rates were extremely low (from $0 \%$ to 3.4\%) (Fig. 7). The -82 bp upstream sequence was capable of driving somite-specific expression of zebrafish $m y f-5$. On the other hand, embryos injected with DNA fragments containing less than 82 bp (pZMYP-62E and -22E) did not give off GFPpositive signals, even when the concentration of injected DNA was increased to $50 \mathrm{ng} / \mu \mathrm{l}$. Based on this evidence, we suggest that the proximal sequence from 
(a) Comparison of the zebrafish MRFs

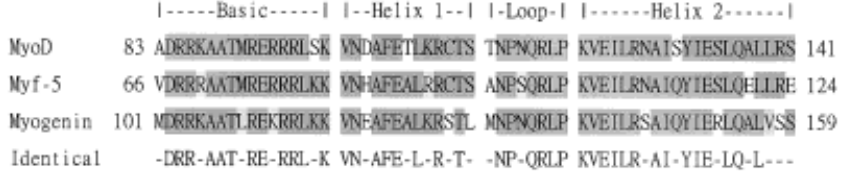

(b) Comparison of vertebrate Myf-5s

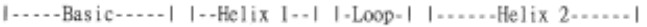

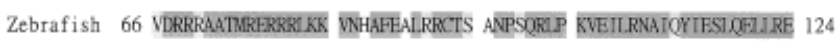

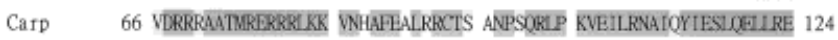

Xenopus 82 TDRRKAATMRERRRIKK WOMFETLKRCTI TNPNRLP ENEILRNAIOYIESLOOLURE 140

Chicken 84 MDRRKAATVKERRRLKK WNAFETLKRCTI ANTNORLP KVELLRNAIRYIESLOELRE 142

Bovine 82 MDRRKAATRRERRRIKK WNOAFDTLXFCTI INPNQRLP KVEILRNAIRYIESLOEIRE 140

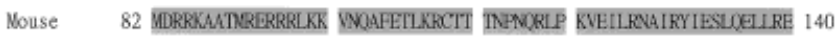

Human 82 MDRRKAATRRERRRIKK WNOFETLKRCTT INPNORLP KVELLRVAIRYIESLOELRE 140

Ident ical -DRR-AATIRERRRL_KK WN-AF--L-RCT- -NP-ORLP KVEILRNAI-YIESLL-LLRE

FIG. 2. Comparison of the basic helix-loop-helix domains of zebrafish MRFs, and the Myf-5 of other vertebrates. Dark and light gray boxes represent identical and similar amino acids with consensus sequence, respectively. Residues conserved in Myf-5, but not in other MRFs, are underlined. Data were obtained from GenBank: zebrafish MyoD (Z36945), zebrafish myogenin (AF202639), carp (AB012883), Xenopus (X56738), chicken (X63250), bovine (M95684), mouse (X56182), and human (X14894).

nt -82 to -1 of zebrafish $m y f-5$ is a minimal cis-element for controlling specific expression. Interestingly, we observed that the proportion of embryos that not only had EGFP expression in somites but also appeared in the translocation of green signals declined sharply for pZMYP-154E- and pZMYP-82E-injected groups (Fig. 7).

\section{DISCUSSION}

\section{Polypeptide Structure Analysis}

In the MRF family of proteins, the bHLH region is the most important functional domain for mediating DNA binding and protein-protein interaction. Zebrafish bHLH domains, MyoD, myogenin, and Myf-5 are highly conserved. In addition, the bHLH domain of zebrafish Myf-5 is exactly identical to that of carp Myf-5 and exhibits 80\% or greater identity with the Myf- 5 of other vertebrates such as Xenopus, chickens, bovine, mice, and humans. However, the entire zebrafish Myf-5 polypeptide sequence exhibited only $54.3 \%$ and $40.8 \%$ identity with those of zebrafish MyoD (Weinberg et al., 1996) and zebrafish myogenin (Chen et al., 2000), respectively. Zebrafish Myf-5 exhibited 92.0, 62.7, 63.3, 61.0, 62.3, and $61.9 \%$ amino acid identity, respectively, with the Myf-5 of carp (Kobiyama et al., 1998), Xenopus (Hopwood et al., 1991), chickens (Saitoh et al., 1993), bovine (Barth et al., 1993), mice (Buonanno et al., 1992), and humans (Braun et al., 1989b). Thus, the bHLH domain is conserved and unique among MRF proteins, but biological function is an attribute of the entire polypeptide. This is consistent with domain-swapping experiments in MRFs (Schwarz et al., 1992; Weintraub et al., 1992;
Winter et al., 1992). As expected, the identity of the $m y f-5$ polypeptide sequence is relatively higher among fish than other classes of vertebrates.

\section{Spatial Distribution of Zebrafish myf-5 Transcripts}

Although somite- and stage-specific transcription patterns of mouse $m y f-5$ have been reported (Ott et al., 1991; Lyons and Buckingham, 1992; Faerman and Shani, 1993), the transcriptional pattern and tissue distribution of $m y f-5$ during early embryonic development of the zebrafish is still unclear. In this study, we used wholemount in situ hybridization with a probe that was specific to zebrafish $m y f-5$. Results showed that this probe did not cross-hybridize with zebrafish myoD. Zebrafish $m y f-5$ transcripts were first detected in paraxial mesoderm at the $70 \%$ epiboly stage $(7.5 \mathrm{hpf})$. At the $90 \%$ epiboly stage ( $9 \mathrm{hpf})$, increased expression of zebrafish $m y f-5$ transcripts occurred at the inner boundaries of the axial mesoderm. From 10 to $26 \mathrm{hpf}$, the signals were observed in adaxial cells, the lateral presomitic cells, and newly formed somites. Furthermore, the numbers of zebrafish $m y f-5$ expressed in the somites increased from 10 to $16 \mathrm{hpf}$ and then gradually decreased, coincident with somite maturation, from 16 to $26 \mathrm{hpf}$.

Adaxial cells, which develop into slow muscle cells (Devoto et al., 1996), are the most medial cells in the segmental plate. They were the only cells expressing abundant levels of myoD and other muscle-specific genes, including myogenin and tropomyosin (Devoto et al., 1996; Weinberg et al., 1996). In constrast, the zebrafish $m y f-5$ gene was only expressed transiently in adaxial cells after segmentation, and zebrafish myf-5 transcripts disappeared in older adaxial cells. Compared to the very abundant expression of zebrafish myoD during somite formation, expression of zebrafish $m y f-5$ is relatively low. In summary, the expression patterns of zebrafish $m y f-5$ transcripts differ from those of zebrafish myoD (as reported by Weinberg et al., 1996) in several important ways. First, expression of zebrafish $m y f-5$ in adaxial cells was low, while zebrafish myoD transcripts were abundant. Second, in somites, zebrafish $m y f-5$ expression was transient whereas zebrafish myoD transcripts were expressed until at least $60 \mathrm{hpf}$. Third, zebrafish $m y f-5$ transcripts were expressed in newly formed somites only, but zebrafish myoD was expressed in all somites. Fourth, zebrafish $m y f-5$ transcripts were highly expressed in the lateral presomitic cells, where zebrafish myoD was not expressed at all.

Mice Myf-5 and MyoD have functionally redundant roles in myogenesis (Rudnicki et al., 1992), a hypothesis supported by findings from Myf-5 (-/-); MyoD (-/-) mutant mice (Rudnicki et al., 1993). However, skeletal muscle development of mice lacking Myf-5 is apparently delayed. We believe that Myf-5 and MyoD each have a unique function in the skeletal muscle differentiation program to recruit different populations of cells into myoblast linkage. The low and transient expression of $m y f-5$ in stage- and somite-specific patterns is highly 
a

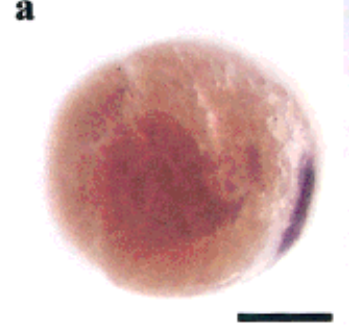

$\mathbf{f}$

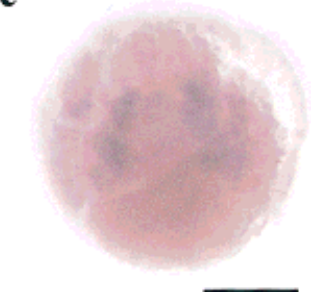

i

b

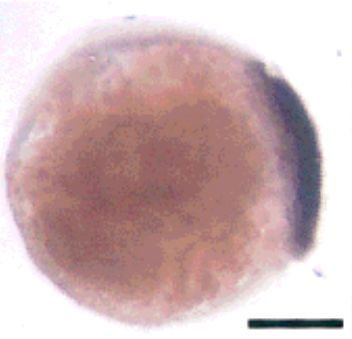

f

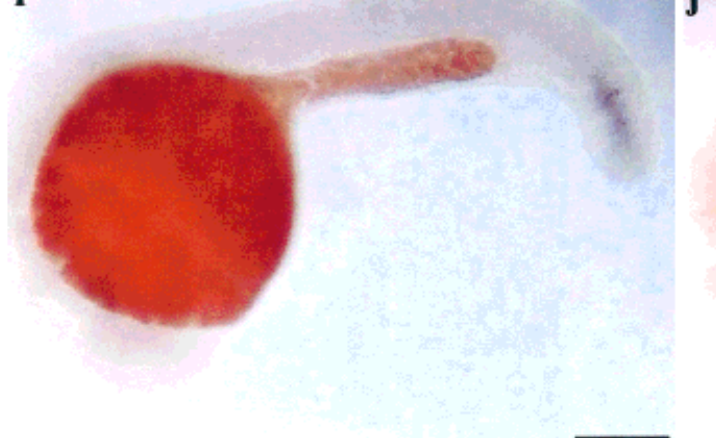

k

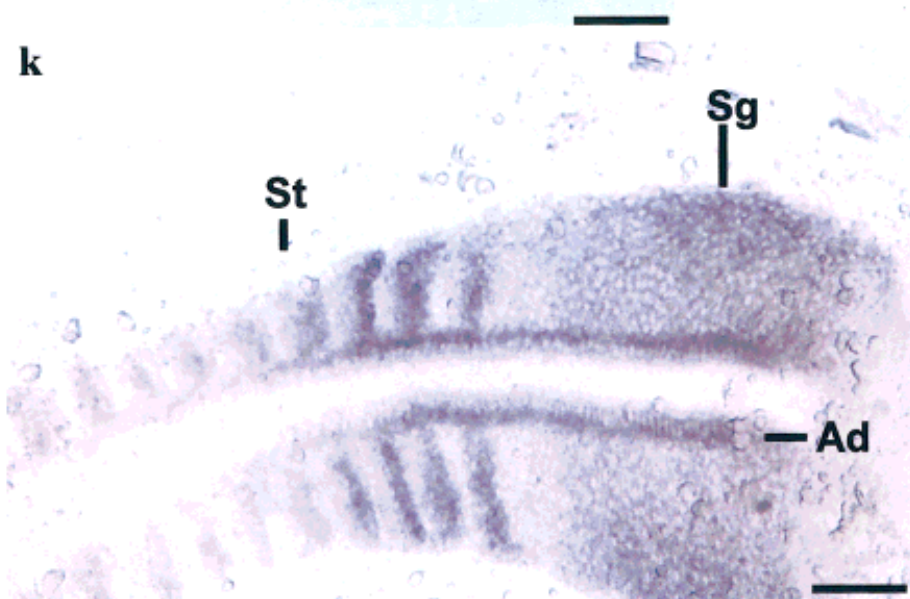

j c

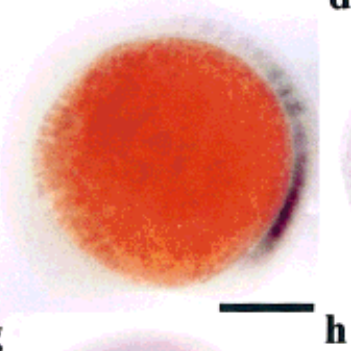

g

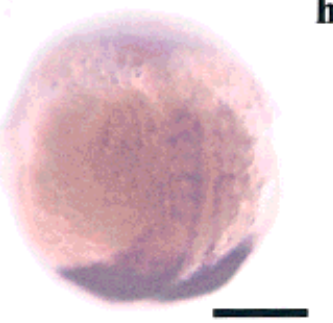

d

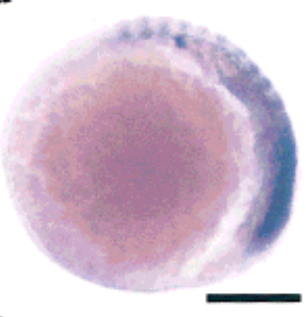

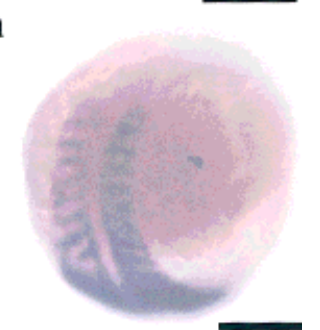
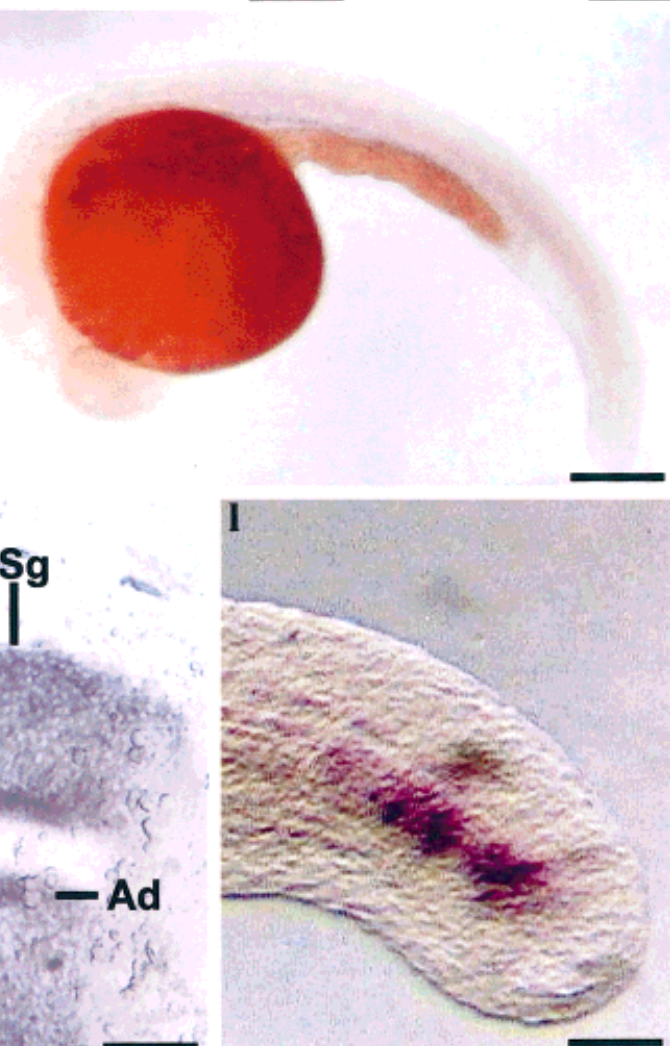

FIG. 3. Expression patterns of zebrafish myf-5 as determined by whole-mount in situ hybridization. Side (a-d, $\mathbf{i}-\mathbf{j})$ and dorsal views (e-h) of embryos at 7.5- (a and e), 9- (b and f), 14- (c and $\mathbf{g}), 16-(\mathbf{d}$ and $\mathbf{~ h}), 24-(\mathbf{i}), 26-(\mathbf{j})$ hpf. Higher magnification of positive signals in 16- (k) and 24- (I) hpf embryos. Zebrafish myf-5 transcripts were first detected in the adaxial mesoderm of embryos 7.5 hpf (a and e), accumulated in the inner adaxial cells by 9 hpf (b and f), and also appeared in the segmental plates (Sg), adaxial cells (Ad), and somites (St) in 14 and 16 hpf embryos (c, d, $\mathbf{g}$ and $\mathbf{h}$ ). Zebrafish myf-5 transcripts gradually decreased from 16 to 24 hpf (i and I) and hardly any zebrafish myf-5 transcripts were detected 26 hpf (j). Scale bars: $\mathbf{a}-\mathbf{j}, 250 \mu \mathrm{m} ; \mathbf{k}, 100 \mu \mathrm{m} ; \mathbf{I}, 50 \mu \mathrm{m}$.

likely in controlling the delicate development and commitment of muscle fiber precursors during zebrafish embryogenesis. It is worthwhile to notice that $m y o \mathrm{D}$ is not expressed in the lateral presomitic cells of the segmental plate, suggesting that lateral presomitic cells may downregulate myoD prior to somite formation.

\section{Temporal Expression of Zebrafish $m y f-5$ Transcripts}

In transgenic experiments, EGFP fluorescent signals were first detectable at the $90 \%$ epiboly stage (about 9 hpf) and were still present at $72 \mathrm{hpf}$. This differed 


\begin{tabular}{|c|c|}
\hline 6212 & CTCACIG AGGCO \\
\hline 152 & ICTATTCTC TATTCTGTTC ATACTICCAT TCATTCATCC TA \\
\hline & BAT CTATTGTCTA TCTATTTATC CTTCTACAAC TG. \\
\hline & TATGGTATAT TTCCCAGTTT GATCATTAGA TGCACTGTAT CTGTAGCACT CTT \\
\hline 72 & AGTTAGAGGG TAACTTTGTT AAAAGOCATG AAAAAAACAA TATTTAAATC ACAGGCAGGC \\
\hline & ATTTATATT GCATGATAGG C \\
\hline 52 & CAGGOGTACT TACTGTAATT ATGAAATGOG ATATGTTCC \\
\hline 92 & AAGGGTTTAA AACATGTCCT TCCAAAGTTA ACACTGAGAT CACTGTTTAT ACCACAACTT \\
\hline 732 & TCTAATGTAG CCTTCOCTTG AAAGCTTTTT C. \\
\hline & COCATAAGAC ATAAAACAGA OGGCTTGAGT AGATTCACCT CI \\
\hline 612 & AAATCTGCCA TCAAAGAAAT AAATGAGCCA GAGAGGACGT GOGCTTAAAA ATGG \\
\hline 2 & CTGAGCTTAA TGCTACAGTT AATGCTACAG TTATGCTTAA T \\
\hline & AAGGAGTAGC A \\
\hline 432 & GGC TATT \\
\hline 72 & TTAACTCAAG GACAGTCTCT CCTTTTCTTT ATA \\
\hline & TTACTTCCTC G \\
\hline 52 & GATGGAACTT TAATGACAGC CAGCGTGCTG GGATTTGAAG ACCTGAGTAT TCGGTGAATA \\
\hline 2 & ATATTCTCCA TTTTGATTAC CCAAGGGOCT TAGACTTAGT TT \\
\hline 32 & GCACACCGTG TGCTGGCTGT GAAAGTGCAC CAGG \\
\hline 072 & TGTAGAGAAA AGAATAACGG CTAAAAGAAC ACCTTTACGA AGTATCAGAG AGTTCGCTGG \\
\hline 012 & AGGAAAATGT ACAAAAGTGT TTTCACACTT CATTTCAGGA CATTTTTGGC TTCATCTGIG \\
\hline 192 & ATGGAT TTTT \\
\hline 1892 & CTTTAAATGG ATATTOCAAG TTAGCTTGAC TGACAGCATA ATGCTGATTA CCACAAAAAT \\
\hline os & GACTTTCAGC TTTTGCCTOG TTTTATCAAA ACAAACAAAA TATGCATTAC AGTGAGGCAC \\
\hline 772 & TA AGTGA. \\
\hline-4712 & AAAATTATAC CGTGGAAATC ACTAAAACTT TGATGATCAC TAAAATGTAG GGTTATACTT \\
\hline 652 & AGOGGACATT TTATTAGGTA CACCTTGCTA GTAOCTTGTT GGGCOCCTTT CAGCTTTCAA \\
\hline-4592 & TAAAGTGCAT CAATTCTTTC TCACAATGAC OCAACAGTGT GOCAGGAAGC ATTCCTTTAG \\
\hline 532 & GTOCAGATAC TGGTCCTGGA ATTGTCAGTA TGTACTGTAA AAAATGCTGG ATTCCACATA \\
\hline 472 & TCAA TTTAGTTAAC TAA \\
\hline-4412 & AAGTGGATTT AACATAAAAC AATTCATTTG TACCAAAAAC ATCAAGAATT GTGTTTTTTA \\
\hline 4352 & TAGCTTATTT GAAGCAAGTA GTTTGAACAA GCAGCAGAAA TCATTTTTTG AGTGATAATT \\
\hline 1292 & CAAATGTCCT GTTCCACCAC ATCCTATAGG TGCTTCACTG AGATTAGGGA GTGCATACAG \\
\hline 232 & TACTAATT GTTTAAAACA TTATCCTGTT TGGAATCCAT TTTTTTGATA GGACCACATT \\
\hline 172 & CATAATGT CAT \\
\hline
\end{tabular}

FIG. 4. Upstream sequence $(-6212$ to $+88 \mathrm{bp})$ of the zebrafish myf-5 gene. Numbers indicate the nucleotide position relative to transcription start site $(+1)$. The transcription start site and the translation start codon (ATG) are shown in the dark gray box. The putative TATA box (TATAAAT), CAAT box (GC(T/C)CAATCT), GC box (GGGCGG), E box (CANNTG), and MEF2 binding site (C/T)TA(T/A) 4 TA(A/G)) are underlined with a single line, dashes, dots, double lines, and a solid line, respectively. The first nucleotide of each unidirectional deletion clone is indicated by an arrow, and a light gray box bearing the name of each clone. This nucleotide sequence is in the GenBank database under accession number AF184166.

slightly from in situ hybridization, in which zebrafish myf-5 transcripts started at $7.5 \mathrm{hpf}(70 \%$ epiboly) but ended at $26 \mathrm{hpf}$. This discrepancy may have resulted from the high stability of EGFP in transgenic embryos.
Fluorescence continued for 2 days, long after the EGFP gene was turned off. We replaced EGFP with d2EGFP (Clontech), which has a higher turnover rate $(2 \mathrm{~h})$. However, the expression pattern of embryos microin- 
CHEN ET AL.

-4112 ACTCTTTACT TTCACAATTT GTATTIGTGA GTATAAAATA TTIGAGTTTC TTACTTTTGT

-4052 TGAAAACAAA CAATATATAT GTAACAATAT ATATATGCTG GTigCAAGTA TTTCGGGTCC

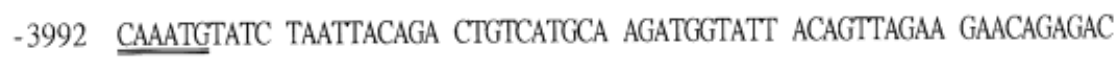

-3932 CAACTGAGCT TTACTGATTA TAGTGCAATT GCATTAAAAA AAATTTTTTT GCCATTTTTG

-3872 TTTATCTCTT TTGTTTAGGC TAACTCATTA GCAGTTIGCA CAGTGATGGT TGCTTAGTAA

-3812 CAAAACTGTA AGAGTACTGT CAAACCTGAT GGCACAATTT AAGATTTCCT AAAACTAAAG

-3752 GTAAAATATG ATTTTGTAAG ATATGATAGG AATCCCAAAT TAAGTTTTGC TTCTGTAATA

-3692 CGAATTTGCA AATAAAATGT AATGCATCAT ATCTTAAGTT TAGACCTAAG ATTAAAAACT

-3632 TATTGTACTA TGOCATCGGG AGACTGTCAT TTTCAAGGAa GCAGTTTGTT GTAAACAGCC

-3572 ATCACGAGAa TCGACTGTGC AatCGTTACA AGGTCATtGT GATGAGTGGT TATTTAAATT

-3512 ACAGGGTTTT TTTGGGGGTT TTTTTTTTTT TTTGTATCAG CTCAAGOCAG TCTGGTGATT

-3452 CTTCTCTGAC CTCTGGTATT ACAACAAGAC TTTCACACAC TGAACTACTG CTCGCTGTAT

-3392 ATGTATAATG TCAAATCCAC TCTTTTTGAA CCTTAGAAAT ACTIGTGTAT TAACATCOCA

-3332 GTAGATCTCA GCTTGAaGAa ATCTTGTTTG GCACCAACAA OCACACCACG TTTATCAOCA

-3272 TCATCTGAAA ACAACTTTTT CTTTCATATT GAAGCTTGGC TTAAATTTTC TTGCCCACAT

-3212 CTGCATGOCT AAATGCATTG AGTTGTGCTC ATTACATATT ATATATTGCT GTGATTAAAT

-3152 ATTTGCATTA ATGTGCAGCT ATGGAGGTTA AACTAATCAT ATGTCCAGGT TCTTTTGTAT

-3092 GAAATTCCTT CCAAAATGTA TACAAACATT TTTTTTTTTG AGAAAAGACA AGAGGGATAT

-3032 GTAAACTGAG AGAACACCAG AATATTAGGA GGTTGAAAAC AAGGACAACT TTAGGAaGTT

-2972 TGTGCATGTC TGTATGGTGC GAAATTATGG AACAGTCTAG AACAGATTCT CATCCAATAT

-2912 CAGGATATTA ATTAATTTAA AAAGTTGTAT AAAAACATTA TTAaGGGATC CACTTTCTTT

-2852 AAACCTTAGA AATACTTGTT TTAAAATGCT GTATGACAAA ATAACTOCTG AACOCTAAAA

-2792 TAAAATCAAT ATGACCAAAA AaCTAGaAaT TAaCCCAGAa ATGTATTTAa TTATACACGT

-2732 TIGTTTTATC AAACCTACAA AAATTGATTA ATTTTGCTTT ATTTTATTAA TTTCTGTAAC

-2672 CTTGAGATGA GAACCGGAGG ACTCTTTAAA ATTCTTTATG ACTAATAAAT GTATAGGACC

-2612 ACCCTAATTT TAGAAGCAAT TTAGACTGGA TTAATCCACT AAAAACAATT CTACTGAATG MEF2

-2552 TGACCCTGTG AAAATGATTA AAAATGTCAG ATTTGGATTT TAAATCTTAT CTGAGTCGCT

-2492 TGGTATTTTA TGCTTATGAa TCTOCAGTGT GCAGTTACGC TGTGAaATCT GCCAGCGCOG

-2432 CACTTGATGA ATGOCTTTTT ATGAaGAGCA CAGCAAACGA TCAGCATCTG GGAAATGATC

-2372 CTTGAACTTG GatTAaAaGC TATTTTATCA GgGCAAACAG CAaGTACTCT TTAGAatGaG

-2312 CATCGCAAAG GTCACTGTAG TCATGCATAT GACATTTGGC TTTTACATAT OCTGTCCTCT

-2252 GATCTGAACT GCTGATTGGA CGTGTCTGAC CTCATCGCAC TGTTGTCCTT GGCTGACCTC

-2192 TCTAGCTCAC CCTCAGTAAC CTGGaGCTTT gGOCAACTCA CACCGaGTAT GTTTACATGG

-2132 GCACAAATAC TCTAATTTAa ATATGATCAC ACTTTACATA CTTTACATTA ACATATCCGT

FIG. 4 (Continued)

jected with $-3 \mathrm{~kb}$ of zebrafish $m y f-5$ fused with d2EGFP cDNA was same as that of embryos injected with zebrafish $m y f-5$ fused with EGFP cDNA, except that the brightness of fluorescence was reduced and the time of the first signal was delayed to $12 \mathrm{hpf}$. Detection sensitivity may be another reason for these inconsistent results because zebrafish $m y f-5$ could be detected from embryos at 7.5 to $32 \mathrm{hpf}$ using Reverse Transcription-Polymerase Chain Reaction
(RT-PCR) (data not shown). In conclusion, we suggest that the temporal expression of zebrafish myf-5 transcripts starts at $7.5 \mathrm{hpf}$, increases substantially up to $16 \mathrm{hpf}$, and then gradually decreases to undetectable levels after 26 hpf. These results support that zebrafish $m y f-5$ polypeptide plays an important role in somitogenesis.

Recently, Hadchouel et al. (2000) reported that all essential regulatory elements for controlling mouse 
-2072 TAaTGTTTTT aCTAGCATGA ACAGTATTTG TACAGCATTC TTCAATICAC TAACATTTAT

- 2012 TAATGGATTA TTAATATCCA AATGTATGCT TTTTAACATT AATGCACAGT GaGTTAGCTA

- 1952 CAACTTGCAT TGAACAACTT CATTTATTCC TTTTTCTATT GGCTTAGTCC TTTTAGTCAT

- 1892 CATGgGTTGC TACAGTGGaA TAaACOGCCA ACTTATTAGC ATATGTTTTA CACAGCGGAT

- 1832 GCCCTTCCAG CTGCAACCCA GTACTGGaGa TATCGTACAA CTCTGTTTCT ATTACCTAAT

-1772 CTTAACAAAC GTAAATAAAT ACAGTAATAA ATGTTTTGTT CATTGCATGT TCATGTAAGT

- 1712 AAATAACTAC ACTGTAAAAA AAAAAAAAAA AAGCTGTAAT TTTACTGTTT ATTTCOGGCA

-1652 GTTGGGGaAC CAGAAAATAA AATGTAAAAT AACGGCCATT AAATTACAGA AATTTACTGC

-1592 AAAATAACAG AGGTTGAATT ACAGAAATTT ACCAGAAATT TTAATTTAAA GAAATTTTTT

- 1532 GTAATTTAAT GTCCGTTTTT TTTTTTTTAC GGTAAATTTC TGTAATTTAA TAGCTATTAT

- 1472 TTTACAGGGT TTTTTCTGGC ACOCCAGCTG COGGAAATAA ACOGTAAAGT TACGGATTAG

- 1412 TTTACAGTGT ACAGTAACAA ATGCAATCTT GTCATAAAGT ATTACCATTA TTTTTATATA

-1352 AagCTATTCT CAGTTTCTCT GGATGTAAAA TTAATCAAAG TGTTTGAATA AAATGTCGAT

- 1292 TTAGTTTTAT TCTTCTAAAT AAAACAATTG TCATTTTGAG CTTGTTTTIG TTTTTTTAAA

- 1232 GATAACTAAG AAGGTGTCAT GTTTTCAGAC AGATTTGCAT TTATTTATTA GACAACACAA

-1172 TATCAATGTT TTAACTTCTG ATTAGTTAAG AAATCAGCAA TTGGTGGAAA ATTCTAATTT

-1112 TTCAATGACA ACAAAGGAAA CGCTTGTTAT TCTGAGCCAT TGGGAATTTC AGGAAAAAAA

- 1052 AACTGCTCAA AATGACAAAA TTGTATTGAA ATTTTAAAGA AATGTTATCA GATATTTATA

-992 GAATTAAACA AATATGAACA TTTGACTCAA ACCTATTTCT AAAACATCCA GTACACATAT

-932 AACCAGTAGT CAATACAATG TAAAATAAAC ATAAATGAGC AGTTTTCCAT ATTTTGTGAT

-872 TCATGTTTTT ATTTTTCOCC AAGTATTTAT ACGTTGGCAA TTGCAATATG GCACCTTGAT

-812 CTTTCTTTAA ACAACTTTTA ACCTTGAAAA AAAAGGAAAA AAGCGACCTT TGTTAACATT

-752 TTTAATTGTT TACAGTGATT TATTGGCAGG GTCGGCGTTG TATATCATGG TACAAAACCA

-692 AAAACCTTGA AATAAGTAGT CATTTTGTGT TAATTGACAG ACTTATTTCT TTATATATTA

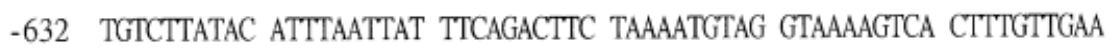

-572 CTGTAAAGTG GaGTTATCAA CATCAAAAAT OGACTACCCA TAATGGÄTT TACAACCGTG

-512 AATAAATGGA AAACACTIGT GAAATACAAA ATACGGAAAC TGCTAATTAA CATATATATA

-452 TAATAĀAATT ATAAAATTAT ATATATATAT ATATATATAT ATATATATAT ATATATATAT

-392 ATATATATAT AATTTATATT CTTTTTTTAT TATTTATTTA TTTACACTTA AAAATATTTT

-332 AAATAAATAT CCTGTAGAGA TCAAAATATA AGaTATTAAA GCTCAAAGTC TACATCTAAa

-272 AATTGAAAGA CACAAAAACA GACATCCGAA GOCTGAGTTT CTTCACGOGA ATGTTTATTG

-212 ATGATAATTC CCTCTTGTAa TGACCGTCAC GCTGCTGAag TGaGTGAGAa ACCACCOCTC

-152 CACACAGATG TGGGAAACTC AGTAGgGGTG TTGGGTTTGG GTGGGGATCT AGATGGTGAG

-92 AGAGGGGGGT CTCTTAGCTC TGTOCTGGOC AATGGGGGCA CGGTCATTAG GGCTGACCAG GC box CAAT box

-32 TGTGGGCOCC $\begin{aligned} & \downarrow \\ & \text { GACATATAAG AAGGGCOGTA TGG̈CACCAGT GCAACCACAC CACTCAGAAA }\end{aligned}$ TATA box

+29 CCTTCAACAC CAAACCAATC ATGGACGTAT TCTCCACATC CCAGATCTTC TACGACAGCA 
(a)

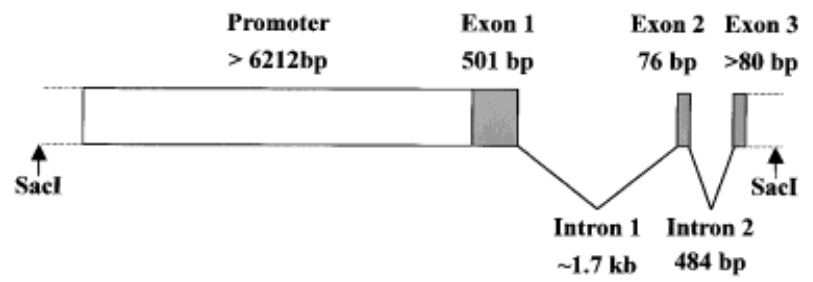

(b)

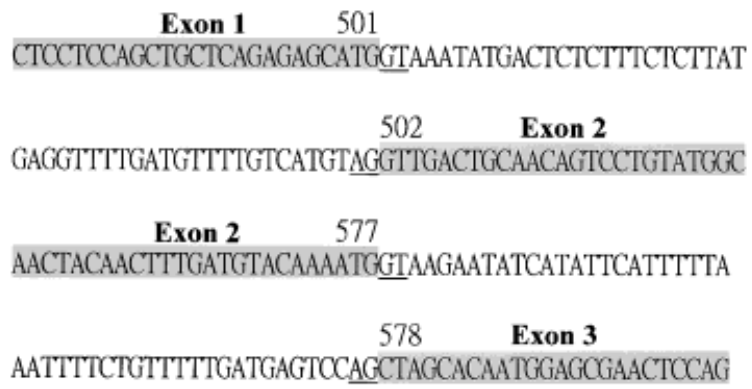

FIG. 5. Partial genomic structure of the zebrafish myf-5 gene. (a) Schematic illustration of the partial genomic structure of zebrafish myf-5 isolated from a recombinant phage clone. (b) Boundary sequences of introns 1 and 2 of zebrafish myf-5. Exons are shown in gray. The GT and AG sequences at exon boundarys are underlined. Numbers indicate the corresponding nucleotide positions of the zebrafish myf-5 cDNA.

$m y f-5$ expression were located within $-96 \mathrm{~kb}$ upstream segment, and a region located between -58 and $-48 \mathrm{~kb}$ could direct $m y f-5$ expression in brain. Daubas et al. (2000) also demonstrated that mouse $m y f-5$ gene was an early axonal marker in brain, besides that myf-5 gene was expressed in somites. In this study, we showed that EGFP driven by $-3 \mathrm{~kb}$ upstream regulatory region of zebrafish $m y f-5$ (pZMYP-2937E construct) appeared green fluorescence in the peripheral layer of the neural tube during the pharyngula stage ( 24 to $48 \mathrm{hpf}$ ). Whether the proximal upstream regulatory region within $-3 \mathrm{~kb}$ of zebrafish $m y f-5$ gene exists an element for controlling neuron-specific expression remains to be studied.

\section{Sequential Expression Among MRFs}

Myogenic bHLH genes are transcribed sequentially during the skeletal muscle development program. Although zebrafish $m y f-5$ and zebrafish myoD signal intensities differed, based on RT-PCR and in situ hybridization, the stages in which zebrafish $m y f-5$ and zebrafish myoD are first expressed might be quite close. However, zebrafish $m y f-5$ transcripts were detectable in paraxial mesoderm and the segmental plate, whereas zebrafish myoD transcripts were undetectable. Therefore, we suggest the expression sequence of MRFs during somitogenesis in zebrafish embryos was Myf-5, MyoD, and myogenin, which is consistent with their expression sequence in carp (Kobiyama et al., 1998), mice (Sassoon et al., 1989), and humans (Braun et al., 1989b).

\section{Cis-Element(s) Controlling the Specific Expression of the Zebrafish myf-5 Promoter}

Despite that mosacism might occur in F0 embryos, the foreign gene driven by zebrafish promoter can be faithfully expressed in the transgenic zebrafish (Ju et al., 1999; Xu et al., 2000; Yoshizaki et al., 2000). We used transgenesis to analyze the promoter of zebrafish $m y f-5$. Results showed that the upstream regulatory sequence from nt -82 to -1 of zebrafish $m y f-5$ is sufficient for controlling somite- and stage-specific expression. Using the Transcription Factors Search program and Palindrome Finding analysis (Vector NTI), an overlapping palindrome sequence, TGGCCA (-67 to -62$)$, a SP1 site ( -58 to -49$)$ adjacent to the CCAAT box (-66 to -58$)$, and a GGGCCC motif ( -29 to -24$)$ that precedes the TATA box $(-18$ to -12$)$ were found within the -82 -bp regulatory region (Fig. 8). Tapscott et al. (1992) reported two regions important for regulating the muscle-specific transcription of mouse myoD. They are (1) a proximal regulatory region that includes a consensus SP1 binding site, a CCAAT box, and an ATAAATA sequence, adjacent to the transcription start site, and (2) a distal regulatory region that lies approximately $-5 \mathrm{~kb}$ from the transcription start site. Our findings are consistent with the results from the mouse myoD proximal regulatory region. However, the upstream, -62-bp sequence of zebrafish $m y f-5$ is not sufficient for controlling the specific expression of zebrafish $m y f-5$. This observation gives rise to the possibility that the -82 to -62 upstream regulatory sequence may contain cis-element(s) required for the specificity of zebrafish $m y f-5$ expression. The conserved CCAAT box, which is important for the specificity of mouse myoD expression (Tapscott et al, 1992), is not included in the pZMYP-62E construct. As a result, it cannot control zebrafish $m y f-5$ specificity. Therefore, we suggest that the palindrome sequences and CCAAT-binding proteins may coordinate with each other to control the specific expression of zebrafish $m y f-5$.

Interestingly, some transgenic EGFP signals shown in the somite also have a tendency for their green fluorescent signals to translocate and form a linear shape during the pharyngula stage. The proportions of embryos for which EGFP signals appeared both somite-specificity and translocation were high for pZMYP-702E-, -526E-, and -290E-injected groups. However, these translocation rates declined sharply for pZMYP-154E- and -82E-injected embryos. Therefore, it is highly possible that a cis-regulatory element located between nt -154 to -290 of zebrafish $m y f-5$ gene may be involved in controlling the translocation ability of progenitor muscle cells. 


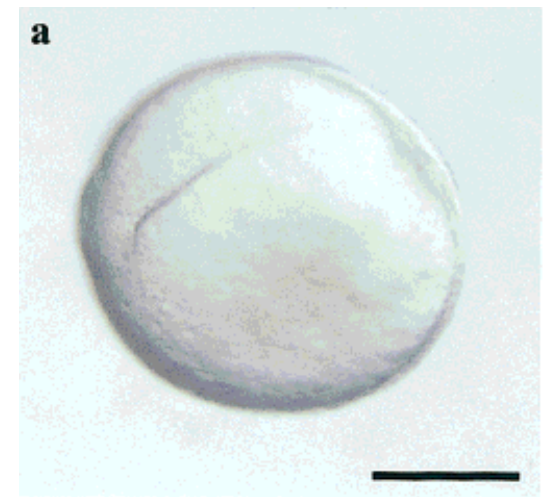

b
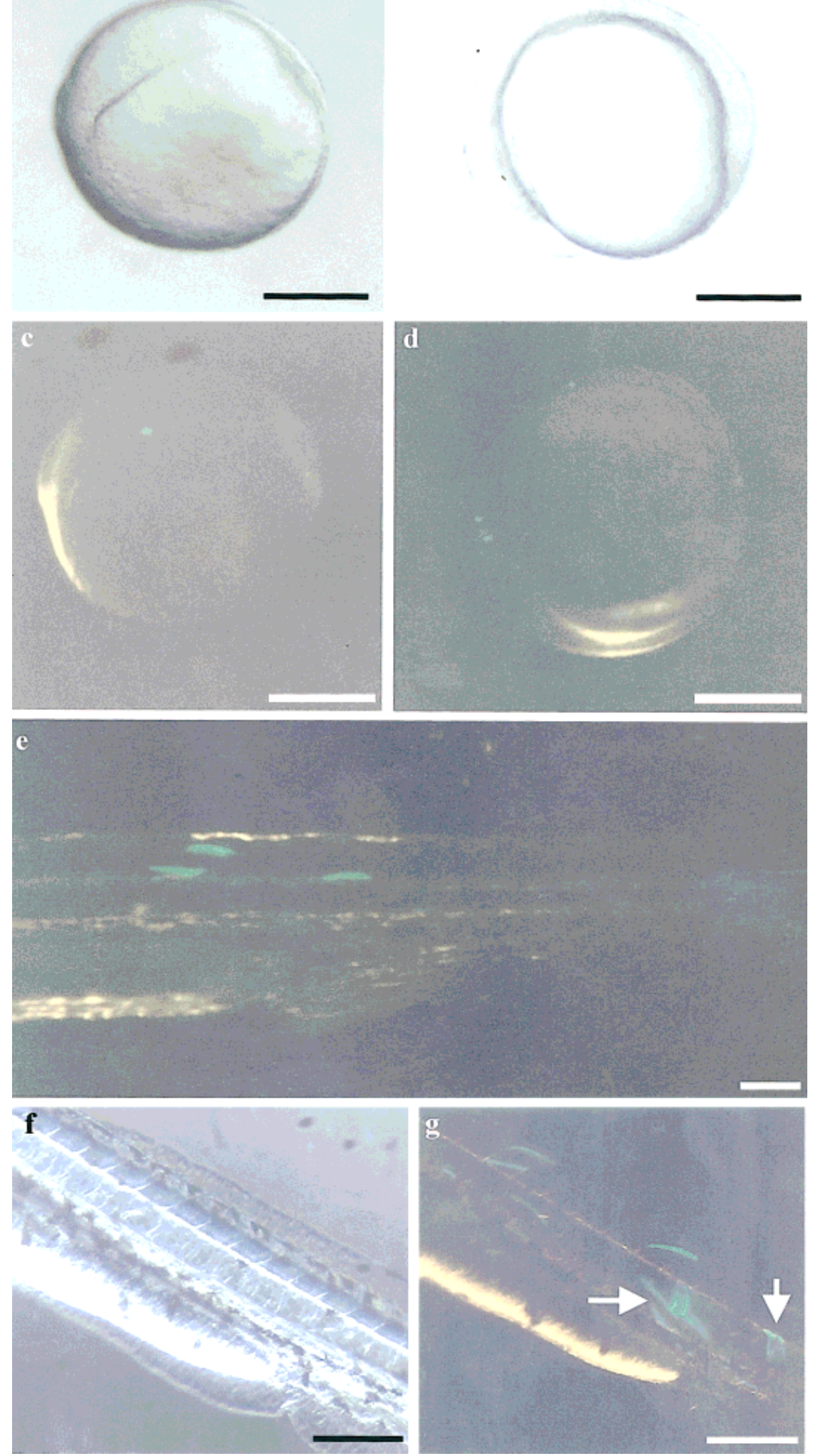

FIG. 6. EGFP expression patterns in transgenic embryos. Fertilized eggs were microinjected with pZMYP-2937E, in which the EGFP cDNA was controlled by a 3-kb, upstream region of zebrafish myf-5. Embryos were photographed under bright field illumination (a, b, and $\mathbf{f}$ ) and in blue light (c, d, e, and $\mathbf{g}$ ). EGFP signals were first expressed as a sharp spot at the edge of the shield during the $90 \%$ epiboly stage (a and $\mathbf{c}$ ). During the early segmental stage, EGFP signals appeared in the somites and segmental plate (b and $\mathbf{d}$ ) and changed in shape from spots to bars. During the pharyngula stage, the EGFP signals changed from bar shaped to linear (e) and remained linear through hatching and the early larval period ( $\mathbf{f}$ and $\mathbf{g}$ ). Arrows indicate EGFP signals displaying on the periphery layer of the neural tube. Scale bars: a-d, 250 $\mu \mathrm{m} ; \mathbf{e}-\mathbf{g}, 100 \mu \mathrm{m}$. 


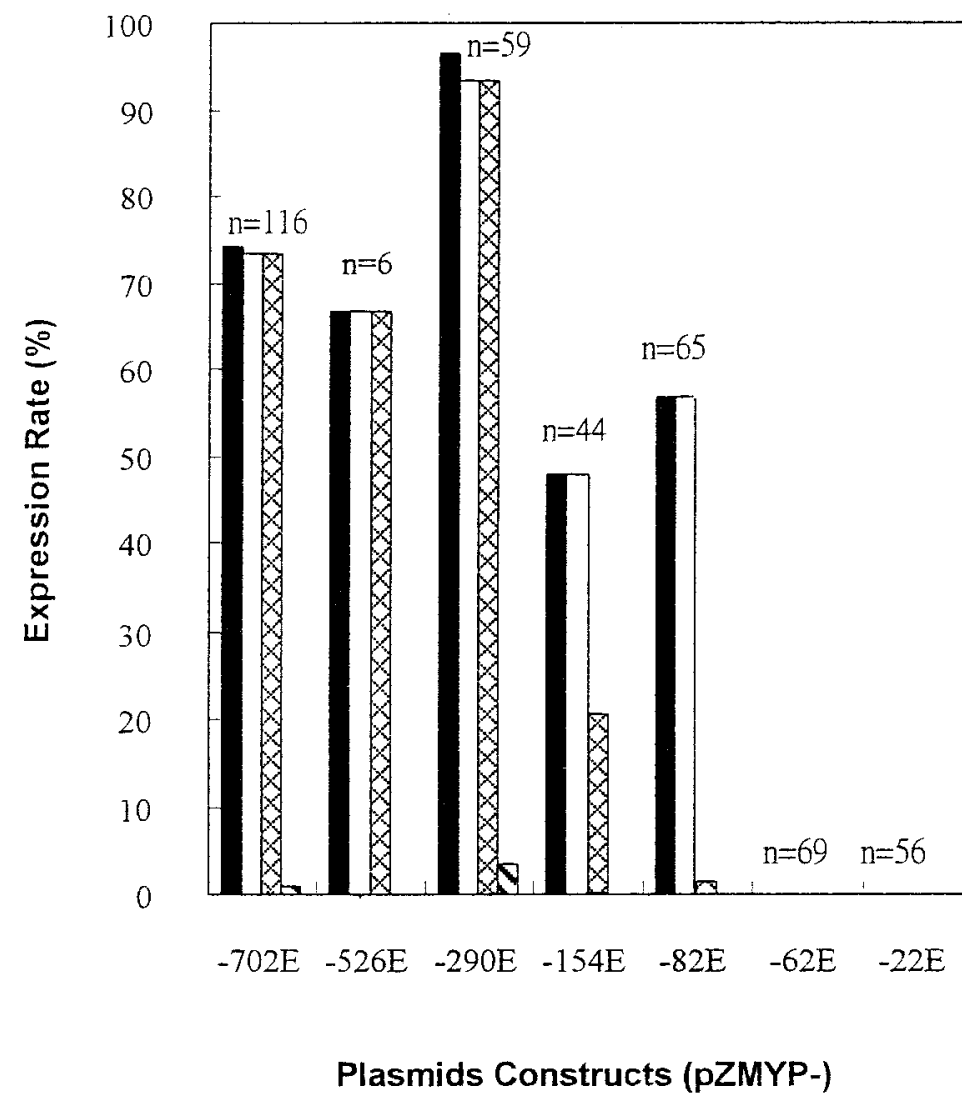

Total expression rate

Somite-specific

expression rate

Expression rate of somite-

specificity and

translocation

$\Delta$ Non-specific

expression rate

FIG. 7. Expression rates of EGFP signals in transgenic embryos. DNA fragments containing different lengths of the region upstream of zebrafish myf-5 were microinjected into the fertilized eggs of zebrafish at a concentration of $25 \mathrm{ng} / \mu \mathrm{l}$. pZMYP-702E, $-526 \mathrm{E},-290 \mathrm{E},-154 \mathrm{E}$, $-82 \mathrm{E},-62 \mathrm{E}$, and $-22 \mathrm{E}$ represent lengths of the upstream region extending from -1 to $-702,-526,-290,-154,-82,-62$, and -22 bp upstream. Calculations of total expression rate (solid bars), somite-specific expression rate (empty bars), expression rate of somite-specificity and translocation (crossed bars), and nonspecific rate (hatched bars) were described in Materials and Methods. The total survival embryos after microinjection of various constructs were listed on the top of each bar (n).

\section{MATERIALS AND METHODS}

\section{Experimental Fish}

Zebrafish $\mathrm{AB}$ strain were kept under a 14-h light and 10-h dark photoperiod at approximately $28.5^{\circ} \mathrm{C}$. After fertilization, the eggs were collected and cultured in an aquarium. Embryonic cleavage number and somite formation were observed with a light microscope to determine the developmental stages based on hpf (Kimmel et al., 1995).

\section{RNA Isolation}

Embryos that had developed for 10 to $96 \mathrm{hpf}$ were pooled and immediately stored in liquid nitrogen. These frozen whole embryos were homogenized with TRIzol reagent (Gibco BRL), and their RNAs were extracted according to the manufacturer's instructions (Gibco BRL).

\section{RT-PCR}

First-strand cDNA was synthesized using the SuperScript Preamplification System (Gibco BRL). Degener- ated oligonucleotide primers were designed with reference to polynucleotide sequences of $m y f-5$ from known vertebrates. A forward primer, Myf5-67F (GG(T/ C)CACTG(T/C)CT(G/C)(A/C)T(A/G/C)TGGGCCTGCAA), and a reverse primer, Myf5-150R (GAGGCTGTAGTATTGCTCCAC(T/C)TG(T/C)TC), were synthesized. Thirty cycles of PCR amplification were performed by Taq DNA polymerase (Viogene). Each cycle consisted of denaturation for $40 \mathrm{~s}$ at $94^{\circ} \mathrm{C}, 1 \mathrm{~min}$ of annealing at $58^{\circ} \mathrm{C}$, and 1 min of extension at $72^{\circ} \mathrm{C}$. The last extension step was extended for 10 min at $72^{\circ} \mathrm{C}$. Amplified DNA fragments were ligated with pGEM T-Easy vector (Promega) and transformed into Escherichia coli $\mathrm{DH} 5 \alpha$. DNA sequencing of both strands was carried out using a bigdyeterminator cycle sequencing ready reaction kit (PerkinElmer Applied Biosystems) with a DNA sequencer (Model 310, Perkin-Elmer Applied Biosystems).

\section{RACE}

First-strand cDNA used for 5' RACE was performed as described above, then homotailed at the $5^{\prime}$-end using terminal transferase TdT (Boehringer Mannheim) and 


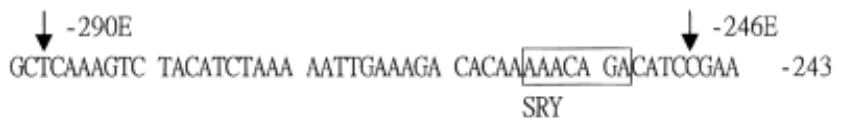

GOCTGAGTTT CTTCACOOGA ATGTTTATTG ATGATAATTC OCHCTTGTAA -193 HFH-2 CdxA GATA-X Oct-1

$\frac{\sqrt{\text { TGACCGTCAC GCTGCIGAAG TGAGTGAGAA ACCACCOCTC CACACAGATG }}}{\mathrm{Nkx-2}}$

TGOCAAACTC AGTAGGGGTG TTGGGTTTGG GTGOGGATCT AGATGGTGAG

IK-2 SRY

Lyf-1 MZF1 GATA-1

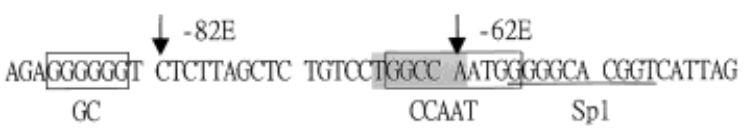

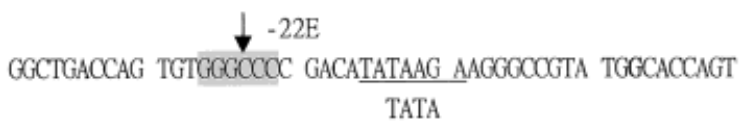

GCAACCACAC CACTCAGAAA CCTTCAACAC CAAACCAATC ATGGACGTAT

FIG. 8. Putative transcription factor binding sites in the $0.3-\mathrm{kb}$ proximal regulatory region of zebrafish myf-5. Numbers indicate the nucleotide position relative to transcription start site $(+1)$. The transcription start site and the translation start codon (ATG) are lettered in boldface. Putative, transcription factor binding sites are indicated. Arrows represent the first nucleotide of each deletion clone. Palindrome sequences are shown in gray boxes.

dGTP. The resulting tailed cDNA was then used to generate double-stranded cDNA by PCR amplification in the presence of a forward primer, RAAPC (GGCCACGCGTCGACTAGTACT $\left.(\mathrm{C})_{9}\right)$, and a reverse primer, Myf5-150R. PCR amplification was carried out as described above with the exception of annealing at $58^{\circ} \mathrm{C}$. The procedure for $3^{\prime}$ RACE was the same as that for $5^{\prime}$ RACE, except that (1) first-strand CDNA was synthesized by a reverse primer, RAAPT (GGCCACGCGTCGACTAGTAC(T) ${ }_{18}$ ), (2) a forward primer, Myf5-67F, and a reverse primer, RAUAP (GGCCACGCGTCGACTAGTAC), were used to generate double-stranded cDNA, and the annealing temperature was $50^{\circ} \mathrm{C}$, and (3) $1 / 50$ volume of the first PCR product was used as a template for nested PCR amplification in the presence of a forward primer, Myf5-96F (GCCAACCCTAGCCAACGCCTC), and a reverse primer, RAUAP, and the annealing temperature was $56^{\circ} \mathrm{C}$. Amplified DNA fragments were subcloned and sequenced as described above.

\section{Whole-Mount In Situ Hybridization}

About $5 \mu \mathrm{g}$ of plasmids containing the insert fragment, which corresponded to nt at positions 188-439 of the zebrafish myf-5 cDNA, were used as template and labeled with DIG RNA Labeling Kit (Boehringer Mannheim). Normal embryos from 3 to $30 \mathrm{hpf}$ were collected and then fixed with $4 \%$ paraformaldehyde for $4 \mathrm{~h}$ at $25^{\circ} \mathrm{C}$. After fixation, embryos were dechrionized, dehydrated in absolute alcohol, and stored at $-20^{\circ} \mathrm{C}$. Embryos were rehydrated by immersion for 10 min each in $75 \%$, $50 \%$, and $25 \%$ ethanol. Rehydrated embryos were transferred to phosphate buffer saline (PBS). Prehybridization, hybridization, and detection procedures were performed with a DIG detection kit II according to the instructions in the supplier's manual (Boehriner Mannheim). All processed embryos were observed under a fluorescent stereomicroscope MZ FLIII (Leica).

\section{Screening and Subcloning of the $z m y f-5$ Genomic Sequence}

A zebrafish genomic library $\left(5 \times 10^{8} \mathrm{pfu} / \mathrm{ml}\right)$ was purchased from Clonetch. Phage plating and titration were performed according to the instructions in the supplier's manuals. The DNA fragment corresponding to nt 188-439 of the zebrafish myf-5 cDNA was labeled with DIG. After hybridization, the positive clones were visualized with autoradiography by exposing the substrate, CDP-STAR (Tropix), for $30 \mathrm{~min}$. Then, a $6.6 \mathrm{~kb}$ SacI-digested DNA fragment from the recombinant phage, which was positive in Southern hybridization, was subcloned to pGEM-3Zf(+) (Promega). The resultant pZMYP6.6 was digested with $X b a$ I to remove the $3.3 \mathrm{~kb}$ upstream sequence to generate the plasmid pZMYP3.3.

\section{Primer Extension}

Primer, Myf5(+1)R (GGATCCGATTGGTTTGGTGTTG) was synthesized, end-labeled with $\left[\gamma^{-32} \mathrm{P}\right]$-ATP (Amersham), and stored at $-20^{\circ} \mathrm{C}$. Approximately $2 \mathrm{ng}$ of mRNA extracted 6 to $16 \mathrm{hpf}$ were mixed with $1 \mu$ probe $\left(10^{3} \mathrm{cpm} / \mu \mathrm{l}\right)$ and hybridized for $4 \mathrm{~h}$ at $55^{\circ} \mathrm{C}$, after which DTT, dNTP, first-strand buffer and Superscript II (GIBCO BRL) were added. The reaction was carried out at $42^{\circ} \mathrm{C}$ for $1 \mathrm{~h}$. All samples were separated after acrylamide gel electrophoresis (containing 8M urea and 6\% acrylamide), dried, and autoradiograped.

\section{Generation of Unidirectional Deletion Clones}

A forward primer, Myf5(-750)F (AGATCTGTGAACATTTTTAATTGTA), and a reverse primer, $\operatorname{Myf5}(+1) \mathrm{R}$, were used during PCR amplification in order to introduce an additional BamHI site into the upstream sequence. A PCR product with a molecular mass of $809 \mathrm{bp}$ was ligated to pEGFP-1 vector (Clontech) producing pZMYP759Et. Then, a 2.9-kb HindIII-ApaI fragment from pZMYP3.3 was cloned to pZMYP-759Et to construct pZMYP-2937E and a $3.3 \mathrm{~kb} \mathrm{XbaI}$ fragment from pZMYP6.6 was introduced to pZMY-2937E to construct pZMYP-6212E.

pZMY-2937E, containing the upstream, $\approx 3 \mathrm{~kb}$ region of zebrafish myf-5 and EGFP cDNA, was purified via Plasmid Miniprep Kit (Viogene). Various deletions of the 
zebrafish myf-5 upstream region were obtained using the Double-Stranded Nested Deletion Kit (Pharmacia Biotech). Salt and DNA concentrations were adjusted to $50 \mathrm{mM}$ and $100 \mathrm{ng}$, respectively, in $1 \times$ exonuclease III buffer. The reaction was carried out at $33^{\circ} \mathrm{C}$ with 2 -min intervals. After agarose gel electrophoresis, deletions of different sizes were selected and their sequences were confirmed using a primer specific for pEGFP-1, (CCCTGATTCTGTGGATAACCGTA).

\section{Microinjection and Green Fluorescence Detection}

EGFP expression vectors fused with different lengths of the zebrafish myf-5 upstream sequence were constructed and linearized with suitable restriction enzymes. The linearized DNA was recovered from $0.8 \%$ low melting point agarose gel (FMC) with the Gel Extraction System (Viogene), quantified by its intensity on the agarose gel, and its absorbance measured with GeneQuant II (Pharmacia Biotech).

Linearized plasmid DNA was diluted to appropriate concentrations with $0.1 \%$ phenol red and $1 \times$ PBS. Fertilized eggs that had not undergone the first cleavage were collected and injected with about $2.3 \mathrm{nl}$ of DNA solution. Cytoplasmic microinjection was performed as described by Stuart et al. (1988). After injection, the eggs were incubated at $28.5^{\circ} \mathrm{C}$.

Transgenic embryos were observed everyday, especially from 9 to $96 \mathrm{hpf}$, under a stereo dissecting microscope (MZ12, Leica) equipped with a fluorescent module and an enhanced GFP filter cube (Kramer Scientific). Photographs were taken with a MPS 60 camera (Leica) and FUJI 400 ASA film. Expression rates were categorized into four groups: (1) total expression rate-proportion of survival embryos with EGFP expression in any cells; (2) somite-specific expression rate-proportion of survival embryos that have EGFP expression in somite exclusively; (3) somite-specificity and translocation rate-proportion of survival embryos that have EGFP expression in somite exclusively and also have translocation of green signal; and (4) nonspecific expression rate-proportion for survival embryos with somite expression that have expression in other cells.

\section{ACKNOWLEDGMENTS}

The authors wish to thank Drs. E. Chiang and B. C. Chung from the Institute of Molecular Biology, Academia Sinica, for helping with whole-mount in situ hybridization.

\section{LITERATURE CITED}

Barth JL, Worrell RA, Crawford JM, Morris J, Ivarie R. 1993. Isolation, sequence, and characterization of the bovine myogenic factorencoding gene myf-5. Gene 127:185-191.

Braun T, Bober E, Buschhausen-Denker G, Kohtz S, Grzeschik KH, Arnold HH. 1989a. Differential expression of myogenic determination genes in muscle cells: possible autoactivation by Myf gene products. EMBO J 8:3617-3625.

Braun T, Buschhausen-Denker G, Bober E, Tannich E, Arnold HH. 1989b. A novel human muscle factor related to but distinct from MyoD1 induces myogenic conversion in 10T1/2 fibroblasts. EMBO J 8:701-709.

Braun T, Bober E, Winter B, Rosenthal N, Arnold HH. 1990. Myf-6, a new member of the human gene family of myogenic determination factors: evidence for a gene cluster on chromosome 12 EMBO J 9:821-831.

Braun T, Arnold HH. 1991. The four human muscle regulatory helixloop-helix proteins Myf3-Myf6 exhibit similar hetero-dimerization and DNA binding properties. Nucleic Acids Res 19:5645-5651.

Buonanno A, Apone L, Morasso MI, Beers R, Brenner HR, Eftimie R. 1992. The MyoD family of myogenic factors is regulated by electrical activity: isolation and characterization of a mouse Myf-5 cDNA. Nucleic Acids Res 20:539-544.

Chen YH, Lee WC, Cheng CH, Tsai HJ. 2000. Muscle regulatory factor gene: zebrafish (Danio rerio) myogenin cDNA. Comp Biochem Physiol B 127:97-103.

Chevallier A, Kieny M, Mauger A. 1977. Limb-somite relationship: effect of removal of somatic mesoderm on the wing musculature. J Embryol Exp Morphol 43:263-278.

Christ B, Jacob HJ, Jacob M. 1977. Experimental analysis of the origin of the wing musculature in avian embryos. Anat Embryol (Berlin) 150:171-186.

Davis RL, Weintraub H, Lassar AB. 1987. Expression of a single transfected cDNA converts fibroblasts to myoblasts. Cell 51:987-1000

Devoto SH, Melancon E, Eisen JS, Westerfield M. 1996. Identification of separate slow and fast muscle precursor cells in vivo, prior to somite formation. Development 122:3371-3380.

Dubas P, Tajbakhsh S, Hadchouel J, Primig M, Buckingham M. 2000. Myf5 is a novel early axonal marker in the mouse brain and is subjected to post-transcriptional regulation in neurons. Development 127:319-331.

Edmondson DG, Olson EN. 1989. A gene with homology to the myc similarity region of MyoD1 is expressed during myogenesis and is sufficient to activate the muscle differentiation program. Genes Dev 3:628-640.

Faerman A, Shani M. 1993. The expression of the regulatory myosin light chain 2 gene during mouse embryogenesis. Development 118:919-929.

Hadchouel J, Tajbakhsh S, Primig M, Chang T H-T, Dubas P, Rocancourt D, Buckingham M. 2000. Modular long-range regulation of $m y f-5$ reveals unexpected heterogeneity between skeletal muscles in the mouse embryo. Development 127:4455-4467.

Hopwood ND, Pluck A, Gurdon JB 1991. Xenopus Myf-5 marks early muscle cells and can activate muscle genes ectopically in early embryos. Development 111:551-560.

Jaynes JB, Johnson JE, Buskin JN, Gartside CL, Hauschka SD. 1988. The muscle creatine kinase gene is regulated by multiple upstream elements, including a muscle-specific enhancer. Mol Cell Biol 8:62-70.

Ju B, Xu Y, He J, Liao J, Yan T, Hew CL, Lam TJ, Gong Z. 1999. Faithful expression of green fluorescent protein (GFP) in transgenic zebrafish embryos under control of zebrafish gene promoters. Dev Genet 25:158-167.

Kimmel CB, Ballard WW, Kimmel SR, Ullmann B, Schilling TF. 1995 Stages of embryonic development of the zebrafish. Dev Dyn 203 253-310.

Kobiyama A, Nihei Y, Hirayama Y, Kikuchi K, Suetake H, Johnston IA, Watabe S. 1998. Molecular cloning and developmental expression patterns of the MyoD and MEF2 families of muscle transcription factors in the carp. J Exp Biol 201:2801-2813.

Lyons GE, Buckingham ME. 1992. Developmental regulation of myogenesis in the mouse. Semin Dev Biol 3:243-253.

Miner JH, Wold B. 1990. Herculin, a fourth member of the MyoD family of myogenic regulatory genes. Proc Natl Acad Sci USA 87:10891093.

Ott MO, Bober E, Lyons G, Arnold HH, Buckingham M. 1991. Early expression of the myogenic regulatory gene, Myf-5, in precursor cells of skeletal muscle in the mouse embryo. Development 111: 1097-1107.

Pownall ME, Emerson CP Jr. 1992. Sequential activation of three myo- 
genic regulatory genes during somite morphogenesis in quail embryos. Dev Biol 151:67-79.

Rhodes SJ, Konieczny SF. 1989. Identification of MRF4: a new member of the muscle regulatory factor gene family. Genes Dev 3:20502061.

Rudnicki MA, Braun T, Hinuma S, Jaenisch R. 1992. Inactivation of MyoD in mice leads to up-regulation of the myogenic HLH gene Myf-5 and results in apparently normal muscle development. Cell $71: 383-390$

Rudnicki MA, Schnegelsberg PN, Stead RH, Braun T, Arnold HH, Jaenisch R. 1993. MyoD or Myf-5 is required for the formation of skletal muscle. Cell 75:1351-1359.

Rupp RA, Weintraub H. 1991. Ubiquitous MyoD transcription at the midblastula transition precedes induction-dependent MyoD expression in presumptive mesoderm of $X$. laevis. Cell 65:927-937.

Saitoh O, Fujisawa-Sehara A, Nabeshima Y, Periasamy M. 1993. Expression of myogenic factors in denervated chicken breast muscle: isolation of the chicken Myf5 gene. Nucleic Acids Res 21:25032509.

Sassoon D, Lyons G, Wright WE, Lin V, Lassar A, Weintraub H, Buckingham M. 1989. Expression of two myogenic regulatory factors myogenin and MyoD1 during mouse embryogenesis. Nature 341: 303-307.

Schwarz JJ, Chakraborty T, Martin J, Zhou JM, Olson EN. 1992. The basic region of Myogenin cooperates with two transcription activation domain to induce muscle-specific transcription. Mol Cell Biol 12:266-275.

Stuart GW, McMurray JV, Westerfield M. 1988. Replication, integration and stable germ-line transmission of foreign sequences injected into early zebrafish embryos. Development 103:403-412.

Summerbell D, Ashby PR, Coutelle O, Cox D, Yee S-P, Rigby PWJ. 2000. The expression of $m y f-5$ in the developing mouse embryo is controlled by discrete and dispersed enhancers specific for particular populations of skeletal muscle precursors. Development 127:3745-3757.

Tapscott SJ, Lassar AB, Weintraub H. 1992. A noval myoblat enhancer element mediates MyoD transcription. Mol Cell Biol 12:49945003.

van Eeden FJ, Granato M, Schach U, Brand M, Furutani-Seiki M, Haffter P, Hammerschmidt M, Heisenberg CP, Jiang YJ, Kane DA, Kelsh RN, Mullins MC, Odenthal J, Warga RM, Allende ML, Weinberg ES, Nüsslein-Volhard C. 1996. Mutations affecting somite formation and patterning in the zebrafish, Danio rerio. Development 123: 153-164.

Weinberg ES, Allende ML, Kelly CS, Abdelhamid A, Murakami T, Andermann P, Doerre OG, Gruwald DJ, Riggleman B. 1996. Developmental regulation of zebrafish MyoD in wild-type, no tail and spadetail embryos. Development 122:271-280

Weintraub H, Dwarki VJ, Verma I, Davis R, Hollenberg S, Snider L, Lassar AB, Tapscott ST. 1992. Muscle-specific transcriptional activation by MyoD. Genes Dev 5:1377-1386.

Winter B, Braun T, Arnold HH. 1992. Co-operativity of functional domains in the muscle-specific transcription factor Myf-5. EMBO J 11:1843-1855.

Wright WE, Sassoon DA, Lin VK. 1989. Myogenin, a factor regulating myogenesis, has a domain homologous to MyoD. Cell 56:607-617.

Xu Y, He J, Wang X, Lim TM, Gong Z. 2000. Asynchronous activation of 10 muscle-specific protein (MSP) genes during zebrafish somitogenesis. Dev Dyn 219:201-215.

Yoshizaki G, Takeuchi Y, Sakatani S, Takeuchi T. 2000. Germ cellspecific expression of green fluorescent protein in transgenic rainbow trout under control of the rainbow trout vasa-like gene promoter. Int J Dev Biol 44:323-326. 